THE SIGNIFICANCE OF A NEUROTIC REACTION

AS A PRECURSOR OF SCHIZOPHRENIAS,

$$
\text { by }
$$

WILLIAM MCCONNACHIE HARROWES, M.B.,Ch.B. 
ProQuest Number: 13905292

All rights reserved

INFORMATION TO ALL USERS

The quality of this reproduction is dependent upon the quality of the copy submitted.

In the unlikely event that the author did not send a complete manuscript and there are missing pages, these will be noted. Also, if material had to be removed, a note will indicate the deletion.

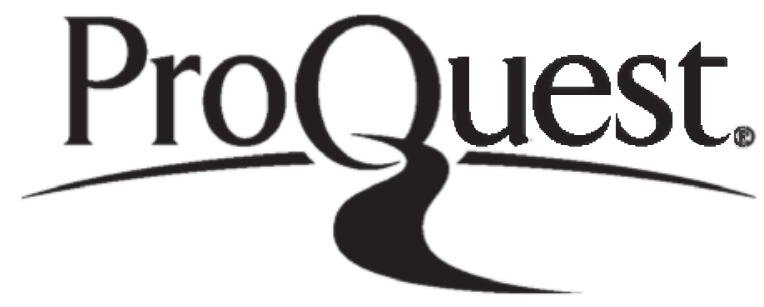

ProQuest 13905292

Published by ProQuest LLC (2019). Copyright of the Dissertation is held by the Author.

All rights reserved.

This work is protected against unauthorized copying under Title 17, United States Code Microform Edition (C) ProQuest LLC.

ProQuest LLC.

789 East Eisenhower Parkway

P.O. Box 1346

Ann Arbor, Ml $48106-1346$ 


\section{INTRODUCTORY .}

The title of this thesis is to some extent explanatory. It is not an attempt to establish a new set of concepts, it is rather an endeavour to combine in a grouping, which has not been sufficiently recognised, a set of existent formulations.

To put this in another way the aim of the following pages is to indicate how much, and to what extent, the connection between two great groups of mental lilness may be stressed. The two groups referred to are the psycho-neuroses, for brevity hereinafter called the neuroses, and the psychoses.

The psychosis which forms a large percentage of the case material which the psychiatrist sees is Dementia Precox (or Schizophrenia) and it is this particular type which has been chosen for discussion.

Various reasons have governed this choice. Dementia Precox is exceedingly common. It has received perhaps more attention than any of the other psychoses and more attempts have been made to elucidate its problems than the problems of the affective psychoses, such as manic depressive insanity. This has been determined by the fact that Schizophrenia has always presented such a marked ideational alteration and such a mass of bizarre thoughts and the whole condition shows such a change in the patient's make up. These have not been obscured by the rapidity of the irresistible rush of the manic states or the 
barren repetitions of the depressive psychoses. There has been, almost from the outset of the recognition of the syndrome of Schizophrenia, an attempt to understand and make sense out of the total behaviour of these cases.

The work of two eminent psychiatrists and their followers has been closely associated with the problems both of the neuroses and the psychosis in question. These are Freud, and Adolf Meyer of Baltimore, and their work has shown the connection between the two conditions in a number of ways to be considered.

Jung, one of Freud's most brilliant pupils has, in his now famous "Psychology of Dementia Precox", drawn a close connection between the psychosis and certain neuroses and has, using the discoveries of Freud, established the bond between them.

Meyer, with a full realisation of the scope, importance, and significance of Freud's work, has elaborated a conception of all mental disease as a definite effort on the part of the patient to meet the demands which $11 f e$ is lmposing on him.

The separation of the neuroses from the psychoses has been growing less sharp and the tendency to-day is to recognise that the distinction is no hard and fast one but that there is a long and gradual series of intermediate stages.

This does not mean that an attempt is being made to 
deny the existence of the neurosis or the psychosis as a clinical entity in its own right. Far from 1t. The majority of the hundred cases reviewed showed no evidence to disprove that a case of Schizophrenia may not exist recognisably as such from the first and the reports of the Cassell Hospital for Functional Mental Disorders indicate clearly that many neuroses never show any indication of psychotic tainting. This last, however, has a bearing on what is to come, for we do not know how many psychotics would never have reached a psychotic reaction had it not been that they were neglected during a prodrome in which they were reacting in a neurotic way.

In the following pages it has been demonstrated that we do see from time to time cases where there has been a neurosis which has subsequently gone on to the development of a psychosis. This is already well recognised but the more interesting point of their common etlology has been overlooked, and the recognisable working of the same cause in producing the neurosis and later psychosis in the same patient has not been clearly seen. No attempt has been made to subscribe wholly to any one psychiatric doctrine. The aetiological factors have often not been traced to their ultimate origins in the Freudian sense (of infantile traumata) and this is held to be an advantage for the symptoms have been taken at their face value, both in the neurotic and the psychotic phases, using of course, well 
substantiated mechanisms of symptom interpretation, and so any misconception has therefore been carried right through any given case and may be held to have thus cancelled itself out.

with the aim in view then, of establishing the close relationship between neurosis and psychosis, the question is gone into from early stages.

The history and delimitations of Dementia Praecox are given with a short sketch of the present-day attitude to this disease. In the same way the neuroses are dealt with. The attitude of the School founded by Adolf Meyer to all mental maladies is discussed and, in the light of its views, the connection between neurosis and psychosis is made.

Finally, cases are quoted to illustrate the theme and certain conclusions are dram. 


\section{THE DEFINITION OF THE TERM DEMENTIA PRAECOX OR SCHIZOPHRENIA -}

Dementia Praecox has been defined by Kraepelin (1) as "a series of states, the common characteristic of which is a peculiar destruction of the internal connections of the psychic personality. The effects of this injury predominate in the emotional and volitional spheres of mental $11 f^{n}$. He separated the condition into four sub groups:-

$\begin{array}{ccl}\text { Dementia } & \text { Praecox } & \text { Paranoid. } \\ " & " & \text { Simplex. } \\ " & " & \text { Katatonic. } \\ & \text { " } & \text { Hebephrenic. }\end{array}$

and these sub-groups still form a useful set of descriptive subdivisions. The simplex type consists essentially of a slow, undramatic, withdrawal from close contact with reality. Kraepelin (2) describes an "impoverishment and devastation of the whole psychic Iffe". The patient gradually reaches a level where he no longer can act as a functioning social unit.

In the paranoid type there is much less "devastation". The personality is maintalned to a greater, sometimes a very considerable, degree. A delusional system is evolved, of a fantastic widespread nature, and it may be frankly persecutory, depressive, or grandiose. The age incidence is commonly later than in the other types. 
The Katatonic sub-group is the most obvious and dramatic of all and is characterised, of course, by the presence of the Katatonic stupor with flexibilitas cerea, mannerisms, perseveration, negativism and bursts of apparently causeless excitement, often with suicidal impulses.

Hebephrenia is the most definitely age-bound of the four groups. It appears at an early age, often at puberty, and in it are seen "incoherence in the train of thought, marked emotional disturbance, periods of wild excitement alternating with periods of tearfulness and depression, and frequently by 1llusions and halluclnations" (3).

All four groups show the general symptomatology of schizophrenia along lines of affect loss and the above sketch is inserted merely to define terms to be employed.

The position is put in this less rigid way by Bleuler (4)"... schizophrenia does not appear to us as a disease in the narrower sense, but as a disease group, about analogous with the group of organic dementias ......... one should, therefore really speak of Schizophrenias in the plural. The disease at times runs a chronic course, at times in shifts; "(or episodes)" It may become stationary at any stage, or may regress a certain distance, but probably does not permit of a complete restitutio ad integrum. It is characterised by a specific kind of alteration of thinking and feeling, and of the relations with the outer world that occur nowhere else. Moreover, accessory symptoms, 
with a specific colouring in part, are something very common". out of these delimitations has come, modified in a way to be described later, the modern view of the condition, defined thus: "Schizophrenia, in its typlcal form, consists in a slow, steady, deterioration of the entire personality, usually showing its self at the perlod of adolescence. It involves principally the affective life, and expresses itself in disorder of feeling, of conduct, and of thought, and in an increasing withdrawal of interest from the environment". (5).

In the two authorities last quoted, the term Schizophrenia is used rather than the alternative "Dementia Praecox", for Schizophrenia in its sense of "mind-split", is more aptly descriptive than the other term, for a condition of which Kraepelin (6) has said "a certain number of cases of Dementia Praecox attain to complete and permanent recovery, and also the relations to the period of youth do not appear to be without exception".

Dementia Praecox, or Schizophrenia, forms an 1mportant problem from the psychiatric standpoint, and from a social economic aspect as well. Cases of this type constitute from 15 to 16 percent of total admissions to mental hospitals in this country, and, what is more, 50 to 60 percent of the permanent population of mental hospitals are schizophrenics. Kraepelin (8) describes $10-15 \%$ of his admissions as being schizophrenics. 


\section{THE HISTORY OF DEMENTIA PRAECOX.}

The evolution of Dementia Praecox, as a definite disease with characteristic features, has been a gradual one, and it has been said with truth that "the history of dementia praecox is really that of psychiatry as a whole" (9). In the article from which the above quotation is taken, Meyer gives an historical sketch which illustrates sufficiently how the disease gradually came to be recognised. In brief, the history of the condition, as outlined by Meyer, is as follows.

In 1674 the dementia type of deterioration was described by Willis, (De Anima Erutorum), who recognised a progressive descent into hebetude dating from adolescence. Pinel described similar cases, and called them "idiotism", and Esquirol used the term "accidental or acquired ldiocy". (Des Maladies Mentales). Later, however, ldiocy became limited to early and congenital defects, while dementia was confined to acquired deteriorations, and these non-organic deteriorations began to be divided into partial and total insanities, into which were incorporated mania, melancholla and confusion. About the middle of the 19th.cent., Morel first used the term "Demence Precoce", and described in it a "stupidite", making of his concept the plcture of a familial degeneracy.

Later came the use of the term "vesania" or total insanity, first used by sauvages and Cullen. This was a disease where melanchol1a, mania, confusion or paranola, and dementia 
made up the symptom complex. This grouping was exclusively adopted as a diagnostic label - and obviously it was a comprehensive category - to which was added neurasthenia as a prodromal symptom. Neurasthenia being used as descriptive of a fatigue syndrome. At this time there appeared, described by Magnan, a "Delire chronique a evolution systematique" - the equivalent of a paranold type of Dementia Praecox - where the degeneration was not marked.

Meantime in Austria and Germany, there was a sorting out, whereby the affective psychoses - the manias and melancolias were separated as recoverable, from a group where the prognosis was less clear.

Morel, in his formulation of the "demence precoce" disease ent1ty, had in mind, unity of cause, course and outcome, in cases of this disease; and in 1863 Kahlbaum made a considerable advance along these same Iines. He attempted a much more complete and all embracing attitude to the patient, in which there was both comprehensiveness and comprehension. In his conception, the general clinical findings of whatever kind were given equal value with the psychic symptoms, and it is here that we find the first frank and declared attempt to regard the patient's illness as a dysfunction of a psycho-biological unit. That is to say, a disorder of the entire organism. He described four groups of disorder.

1. Vesania, equivalent to Dementia Praecox, but including 
in it a progress of the type already mentioned ( $v$.supra "vesania").

2. The Vescordias (wrong heartedness) the affective psychoses of the manic depressive type.

3. The Dysphrenias, equal to our toxic exhaustive reactions. 4. The paraphrenias, psychoses determined by age.

Neophrenia, in infancy.
Hebe
Presbjo "

Th1s was criticised as being impossible to square with practice and not borne out by clinical evidence. Hecker described Hebephrenia as one of Kahlbaum paraphrentas, the age bound disorder, and at about the same time, Kahlbaum described Katatonia as a vesania similar to paresis with motor symptoms and in this way the grouping that he had set up was rendered less firm. Thereafter for some time Kahlbaum was lost sight of in what Meyer calls a "paranoification of psychiatry", by Westphal, Krafft-Ebing and Schule, during which paranolas of various types came to occupy the place of dementia precox. This was in response to a psychology of emotion, which tended to create a separation between affective and intellectual disorder. The manic depressive group was included in the affective series, and under the paranolas came part of the older vesania syndrome with paranoia as a primary state. At the same time, in America, Spitzka, Hammond and Pick began to describe a progressive primary dementia, and about now began Kraepelin's work 
in this connection.

In 1893 he described dementia precox as synonymous with Hebephrenia (Hecker) and also included catatonia, and dementia paranoldes: and in a review of Zlehen's work, which was full of a series of paranolas, he grouped all primary and secondary dementias in a progressive deteriorative dementing process: thus Dementia Praecox made its debut at the hands of Kraepelin in 1898 as a result to some extent of the work of Morel, Kahlbaum, and Hecker. The alm of Kraepelin, as of the others, (Morel, Kahlbaum, Hecker) was a unfformity of cause, course and outcome. At the time, the description met practically none of these but at any rate a definite concept had been brought forward. 
THE DEVELOPMENT OF THE MODERN VIEWS.

Up till this point all the ambitions had been to secure a disease entity with a name, but, from now on, attention began to be directed to attempt an understanding of the condition. In 1896, Meyer, working at the Worcester Hospital, developed a general analytic-synthetic principle, which was gradually expounded into "a conception of dementia praecox as depending on a special personality and constitution, on habit disorganisation; leaving the internal working and development of the functional and structural deficit as possibly incidental, still to be worked out". This led up to 1907 when Jung and Bleuler entered the fleld. Jung developed the determination of symptoms by complexes (pathogenic groups of 1deas), endowed with a strong emotional tone, suggested a toxin, and hinted at special personality types. Eleuler looked to a disease process, generalised as a toxaemia or localised as a gliosis, causing associative disorders, but later he abandoned this narrow view and stated "The term schizoid designates a type of mental nature and reaction which is more or less present in everybody and in its morbid exaggerations constitutes schizophrenia".

About this time many contributions from various points of view were made. Stransky developed the conception of an "intrapsychic atoxia" as an explanation of the affect dysharmony and in 1914 Berze suggested a primary insufficiency of mental activity - another way of stating the case for a constitutional 
defect.

Much earlier, however, Freud had described a case of hallucinatory paranoia and some years later, in 1912, he published a paranola study. In these he took up a dymamic attitude fore-shadowing what was to come later, at the hands of Kempf, who, in 1920 introduced, with not so much interest in formal grouping as in the etlological process, problems of repression, regression to more primitive thought processes, and fixation. In Germany, during the perlod of Kempf's work, investigation was being carried out along unimaginative and almost purely descriptive lines, but, at the same time, Kretschmer took up, in a new and stimulating way, the constitutional factor; and Kahn developed the heredity factor to the point of postulating two heritable factors, first a disposition to the disease, and second the actual progressive process. These are only two of a large series of investigative avenues that have been, and are being, pursued. The most important have been the Abderhalden tests, Mott's work on gonadal influences, which is still a subject of controversy, Von Monakow's suggestions as to lesions of the choroid plexus, and the work of Bruce and cotton on focal sepsis as an etiological factor.

At the same time, advances were being made along other, and probably more fruitful, lines at the hands of Meyer and Kirby in America, and by Hoche in Germany. The lines of discussion and theory pursued by these workers led up to a recognition of 
Schizophrenia as a condition where the aetiology was, if not uniform in quality or quantity, yet constant in its method of activity, so that it produced a recognizably similar group of cases. And here began to be formulated the principle of mental illness as a definite, purposive reaction in response to various stresses and strains of a very varying nature. To some extent Kahlbaum had hinted at this and the principle was accepted by Kraepelin. So it was that the present-day attitude to the problem of Schizophrenia became established.

The development of Schizophrenia as an entity has followed a course typical of the elucidation of many disease problems. First a recognition of certain of the symptoms, then an attempt at establishing a uniformity from an etiological, progressional and prognostic standpoint, then guesses at aetiology, and now, at the present, a position where "reaction types, the factors entering into them, the prognosis and the therapeutic assets are given equal and relatively independent consideration" (10).

This attitude is being more widely accepted and its essentially dynamic purposeful nature gains a further assurance from the tendency freely to accept a hormic psychology along lines laid down by McDougall.

In the fleld of psychiatry, however, there can st1ll be felt the influence of older authoritative formulations and it is not recognised clearly to what extent many of them may be 
integrated into the reaction type concept save as descriptive patterns.

The striking contributions of Kraepelin, clearing up a confused situation, and establishing the place of Dementia Praecox as a hard and fast nosological unft, has had a profound effect, even although he later subscribed, as has been stated, to a less rigid doctrine. This effect has been along the lines of insistence upon Dementia Praecox as a condition of itself with no shading off into other types of psychosis, a rellc of the earlier cleavage of the vesania group and, still less, with any association with the nouroses.

Recently, however, two tendencles are noted. Of these, the growing spread of the reaction-type attitude, is the first, and the second, its logical outcome, is a growing willingness to affirm the existence of the borderline case, (11). In support of this we have Meyer's statement that we must admit the existence of an unclassified residuum in our case material.

In a group of schizophrenias certain of these borderIine cases emerge as those where the schizophrenia syndrome is complicated by the presence of neurotic symptoms, elther in the prodrome, during the psychosis or during remissions in the psychosis.

Tainting with other types of psychotic reaction must of course be admitted into the unclassified residuum. The neurotic symptoms seen are those that, by themselves, would constitute any of the well defined groups of the 
psycho neuroses, that is to say Neurasthenia, Hysteria, The Obsessive Compulsive States and the Anxiety-States.

In terms of a "Reaction Type" psychiatry as evolved by Mejer, the neuroses and the psychoses are described as "part" and "total" reactions respectively. This division, of course, arises out of a setting in which all mental abnormalities are regarded as responses to stimull or reactions to social-economic demands both internal and external.

The development of a neurosis leaves the patient the same individual objectively, while the psychotic patient undergoes a marked objective change from the personality aspect. From a subjective point of view also, the difference is similar. The world in which the neurotic lives is still the world of reality, while the psychotic lives in a world of his own to a greater or lesser extent, and this is especially true of the schizophrenic where disintegration of the personality is so marked a feature. The difference is one which embraces all the aspects of the individual as a psycho-biological unit, and it must be combined with the conception of a long range of graduations from the normal level of mental activity, along lines of reasoning, differentiation and abstraction, back to the more primitive one of feeling, concreteness and perceptual thinking seen in the regression of the psychotic.

The essential point is the patient's relation to reality: and it is in terms of this that the use of "partial 
reaction", to indicate a neurosis, and "total reaction", to indicate a psychosis, becomes justified. "In a psychosis reality is changed qualitatively ..... In the psychoneurosis reality remains unchanged qualitatively, although its value may be quantitatively altered (diminished)" (12). 


\section{THE HISTORY OF THE NUEROSES.}

The neuroses have a lengthy history. Charcot, with his neurological bias, was amongst the first to attempt a sorting out of the confusion regarding these types of reaction. He discovered the power of hypnesis to reproduce the lesions of hysteria, and thereby indicated their psychogenic origin. But he believed that only in hysterics could this be done, and regarded hysteria as a degenerative phenomenon.

Next came Janet, who used the analogy of internal tension holding the stream of conscious activity together, and by the lowering of this tension, with the consequent disintegration, he explained the mechanism of hysteria, and of neurasthenia.

Freud's doctrines of repressed memories, in the subconscious, for the most part of sex traumata or frustrated sex activities, reaching consciousness disguised and with an emotional component, or as a physical stigma, are so known and so elaborate that they cannot be gone over fully in a sketch of the history of the neuroses but the are of paramount importance and they are herein taken as understood. Dejerine, whose work suffered from its temporal contiguity to the dramatic theories of Freud, has postulated a mechanism where emotion reverberates throughout the whole psyche, and attaches itself to organs, and groups of organs, producing his series of functional nervous disorders, tachy-cardias, anorexias, respiratory ties and so on 
but he finds his etiological factor in the recent past and in the conscious mind.

It is to Froud, Breuer, and later to Jung, that we owe the conception of complex formation, where ideas, or groups of 1deas, repugnant to the ego, operate unconsciously to produce the various neurotic symptoms, with the affective component added as a result of the internal conflict between the pathogenic ideas and the ego. This view, with modifications, is now widely accepted, and its part in the aetiology of both psychotic and neurotic symptoms is recognised. Here is the first real recognised point of contact between the neurosis and the psychosis and the elaboration of 1 t is due to Jung who has demonstrated the striking simflarity between nourotic and psychotic types of reaction in "The Psychology of Dement1a Praecox".

The work of Adler has to be given a place to itself. He suggests that the neurosis is in all cases a failure to meet Iffe's demands due to the inferiority of some organ or organs. He Indicates also that the neurotic reaction may be an overcompensation for such an inferiority and that the neurotic patient shows in his symptoms the attempt to overcome his handicap That this is true in some cases is evident but its universal application is still in doubt.

The classification of the neuroses now generally accepted, is that of four main groups. 
manifestations, such as paralysis, seizures, fugues, somnambulisms, and accompanled by the mental calm, the belle indifference of Janet, and the condition as a whole is regarded as the operation of a partially autonomous complex which has become split off, dissociated, from the total personality.

The Anxiety States. These were separated by Freud into Anxiety neurosis, and anxiety hysteria. In the former the affect of fear has a physical component of tremor or palpitation, and in the latter, the fearful affect is linked with some external object. It is claimed that this distinction is not posible clinically, and that it is better to refer to this group as the anxiety states, which correspond to the anxiety-neurosis of Freud. The Hypochondrias may be regarded as a sub-group, where the preoccupation is of somatic dysfunction, although Freud suggests a connection with the obsessional states.

Neurasthenia has been described by Meyor as a condition with "mental and physical fatigue associated with sensations of pressure in the head, poor memory, inabillty to concentrate, irritability of temper, increased reflexes, poor sleep and various aches and pains":

Freud, of course, unhesitatingly ascribes onanism as the cause of this condition, but more weight is now being given to the role of continuous emotion induced by whatever cause in producing nourasthenia as a fatigue syndrome. 
States, where the patient's content of thought is constantiy preoccupled by some thought, or the thought of some action, apparently indifferent and meaningless, endowed with affective significance which is disproportionate. The affect may be anxiety, shame, or a hypochondriacal depression. The obsessive thought is merely a meaningless substitute for some repugnant memory

This brief description has been made merely with a view to defining terms to be frequently employed. 


\section{THE REACTION TYPE THEORY.}

The Mlerian concept, essentially commonsense, is one in which, to use Meyer's own words again (13) "reaction types, the factors entering into them, the prognosis and the therapeutic assets are given equal and relatively independent consideration". The term "reaction type" is self explanatory. It indicates that in regarding the Schizophrenias as "reaction types" the disease is looked upon, not so much as a pathological process with a definite lesion back of it, as a maladaptation, a malreaction of the individual to his environment. The individual here is taken to indicate the entire organism as a psychoblological unit. And it is here that a frankly pluralistic outlook is a preventive of a narrow view for, by adopting a dynamic and psychoblological standpoint, the valuable and suggestive findings of the workers along physlological lines may still be incorporated into the concept.

Man's whole life is a reaction to his environment, which latter must, in the nature of things, be constantly changing. If he reacts improperly, or falls to adapt, he ceases to be a functioning social and economic unit, his orientation into reality becomes shifted, and if his malreaction takes place along certain lines, now more or less defined, he can be grouped among reaction types of a schizophrenic nature.

The handicaps against proper reaction and adaptation 
are legion. "The individual may be loaded in various ways - by inheritance, by physical defects of an endocrine disorder or some grosser kind, by intellectual deficiency or what not - but none of them is in itself a sufficient cause of schizophrenia. It is only when the subject, whether handicapped or not, has to face the usual concrete problems in his journey through life that reactions can appear which cumulatively lead to one of the numerous conditions which have been included under the designation of Dementia Praecox or Schizophrenia. It was from a careful study of patients, and especially of their history before any breakdown was recognised by friends or relatives - a line of investigation commonly neglected - that Meyer concluded that schizophrenia is the end result of an accumulation of faulty habits of reaction" (14).

As Jung has sald the complexes which cause the neurotic to break down are those which the normal individual has successfully over come.

The reaction type theory has been purposely stressed as what follows depends to a great measure on a clear conception of what it means.

It is the idea of a cumulative and progressive series of faulty responses that leads naturally on to the search for a gradual onset, and this is not a fruitless one. But the period during which the patient is noted to be "queer", and before he develops a declared psychosis, the prodromal period, is one in 
which a multitude of trends are seen.

In the review of cases of schlzophrenia the presence of neurotic symptoms can frequently be seen during the prodromal period, in remissions, or during the psychosis. It is held that this period is of the utmost importance and that at present its significance is not given the attention it deserves from the point of view of mental hygiene and therapy. 


\section{THE RECOGNITION OF NEUROTIC SYMPTOMS.}

The recognition of this neurotic coloring finds support as far back as the time of Cowles in 1885, who added to the vesania concept, neurasthenia, as an initial stage, and later authors have confirmed this. Blanchi (15), who did not subscribe to the Dementia Precox classification, yet, including it in his group of sensory insanities mentions it in a paragraph where he says "Dementia Precox, as was remarked in a recent and interesting monograph by Jahrmarker, of the clinique of Tuczeck, is met with in many well defined maladies, including even hysteria". Kraepelin describes a hypochondriasis in the prodrome. Bleuler (16) puts it thus "The beginning of schizophrenia is in reality usually furtive. Even though the disease becomes obvious to the relatives first through an acute attack, a good anamnesis usually reveals certain previous changes of character or other schizophrenic signs. Whether the inclination to retirement, often noticeable even in childhood, combined with a certain degree of irritability, is an expression of a disposition or the actual beginning of the disease cannot be decided. In many cases ...... neurasthenlc, hysteric, or compulsive neurotic symptoms are for jears mistaken for the disease and treated unsuccessfully".

These authoritative statements, with the clinical ovidence, make the existence of neurotic symptoms clear and the point has been further investigated along other lines. Hutchings, 
Cheney and Wright (17) with investigation far back into the Iife history of the patient along Freudian lines, claim to have discovered a constitutional loading along lines of improper sex development. They suggest that oedipus mechanisms, with homosexual and narcistic trends, are persistent, and that they appear In response to situations demanding adult reactions, and manifest themselves as a progressive disintegration along regressive and schizophrenic lines. It is a truism to say that Freudian symbolism, and regressive sexual phenomena are very of ten seen in Schizophrenia, but the implication is important when we consider the existence of these same mechanisms in the neuroses.

This leads naturaliy on to a suggestion of some possible added factor, endogenous or exogenous, determining the development of a schizophrenia as an eplphenomenon, upon what began as a neurosis.

The converse of the general proposition, namely the presence of schizold manifestations in the neuroses, recognised some time ago by Jahrmarker, (v.supra) has also been expounded by Brill (18). He says "I thus discovered any number of patients who were neither clear cut schizophrenic nor psychoneurotic" and he adds "These cases ...... represented all sorts of transitions from the praecox to the psychoneurotic".

He, too, like Hutchings, Cheney and Wright, looks back to homosexual narcistic trends, early established but with a constitutional tendency to an affective holding up as the 
schizoid component, and, of course, affective rigidity is a very frequent finding in the schizold or schizothymic personality (1.e., the type of personality who tends to be schizophrenic).

To some extent, insistence on a constitutional, or personality factor, is merely the importation of the diathesis theory, so well known in general medicine, into the field of psychiatry.

An interesting aspect is seen in the statement made by Stack sullivan (19) with reference to "periods of depression, anxiety or apprehensiveness occurring during enforced pauses in the compensatory program". This is more than a hint at a mechanism. It is more than likely that many of these nourotic symptoms of the anxiety type, in the prodrome, arise, during checks, it is true, but they arise from the unpleasant effect thrown up by frustration of instinctive drives or by falling short of these, especially where they are drives not appropriate to the level of general psychic, or more especially, psychosexual development. But this is merely a corroboration of Freud's doctrines. Sullivan, however, adds "It is a study in Itself to make out the forces which push the psychopathic individual in some instances into schizophrenic psychoses of a major variety, in yet others into brief episodes of excitement uncomplicated by the schizophrenic phenomena" and he also says "Patients often report that they have been unhappy for a long time before the appearance of frank D.P.experience." 
one hears again and again of 'perplexity', 'Indecision', 'lack of confidence' in the prodromata of all types of psychosis.

We can not as yet make out these forces. We can avoid the difficulty by calling it constitutional schizoidism or schizothymia and in this we have the support of Kretschmer (20) as well as a large mass of evidence to show that schizophrenias in siblings breed true, and that there is such a thing as an inborn tendency to schizophrenic reaction, or we may look in a more commonsense way at the whole problem, and assess all the factors entering into the reaction.

None would deny the essentially dynamic nature of the neurosis. A careful survey of the personal equation will soon reveal what the patient is trying to do with himself, and, in the present day attitude to Schizophrenia, we see the same attempt on the patient's part to solve a problem, to build a Iife structure with imperfect tools, on a bad foundation, or with an improper conception of what the edifice should be.

In the neurosis the process is active and the neurotic patient is in proper perspective to reality. In the Schizophrenias the reality perspective becomes lost, instinctive drives become disintegrated within the total, there is the striking affective change which has been given so much value as a diagnostic point. Wherein lies the factor determining the progress in the one case to a Schizophrenia and in the other to a nourosis with intermediate states between? Is 1t, once more, 
constitutional schizoidism, or must we look merely to the difficulties which the patient is up against. 


\section{CLINICAL EXAMPLES.}

The following case observed personally over a period of years, lllustrates the type of transition which may take place. Nothing could be more definitely a dynamic neurotic solution of a problem than the symptoms which marked the onset of the illness in the first patient, and which persisted over a period of 4 years before schizophrenic symptoms manifested themselves.

Case I. A woman of 32. She was a pianist and an L.R.A.M. of high executive ablilty and one of a professional pianists team. A marked fixation had taken place on her employer who was much older than she. On the eve of a recital he asked her to stand down in favour of another artist, and she did so without demur, without scene or argument, with him, or at home. This response is noteworthy as it is an example of an effective holding back. Within a few days she developed an hysterical palsy of her right hand and arm. At the same time a personality change of a type was seen along the following lines.

Delicate as a child, she lost school contacts through Illness and soon showed herself, at the age of about 8 , as emotional and a very poor mixer. As she grew up this persisted. She had little emotional outlet in reality. She had no heterosexual adventures of any kind, the family described her as boing apart from them, reserved, different, snobbish, haughty and showing the "proud distance" of Kretschmer's schizold 
personality. In her music she was indefatigable, she worked at it tirelessly, and her physical frailty seemed only to increase her determination to pursue her practising, and she would do elght or nine hours a day. This is, of course, very significant of a schizold trend, as is the personality picture. This, however, changed somewhat with the appearance of her hysteria. She became less reserved, and more friendly, her family felt that she was nearer to them than she had been formerly. The palsy which she developed involved her whole right arm from the shoulder downward. It was a true hysterical condition, for it was associated with an unappreclated anaesthesia to all stimuli and it did not correspond to any of the true nerve palsies. For example she could shrug her shoulder but could not operate the diltold. On one occasion she fell while crossing a stream rather than use her arm to grasp at a support. At the same time, she had periods of partial dissociation, and during these she would go upstairs to the drawing room and play the plano with vigour and zest for an hour on end. After such a period she would deny that she had been playing or would say she had been using her left hand only.

It should be noted that the palsy could easily be grouped under any of the types of stigmata suggested by Freud. In the right arm of a pianist we cannot deny the existence of a 'somatic preparedness' or the phallic symbolism of a rigid arm 
while the third possibility of onanistic acts carried out by that hand cannot be disproved.

Her rationalisation of the condition was that she had a neuritis of her arm due to excessive playing. She sald that she would have had to give up in any case. She never complained of pain in the arm and she never blamed her employer.

The condition lasted for four years in a pure state, and at the end of that period she began to show symptoms of a more ominous type. The first of these was a tendency to retire to bed and remain there for days - a retreat from reality - and at times she had spasmodic affective releases in outbursts of crying and screaming. She called in the family doctor, and showed signs of a fixation on him also.

But it was not until 7 years after the appearance of these, the first definite psychotic symptoms that she broke down so utterly that life on the outside was no longer possible. People began to talk through their feet to her, her brother had given syphilis to the mald and the maid had given it to her, she began to use obscene language, and the palsy began to disappear.

The further development of the psychosis was along typical lines. She had periodical outbursts of violent grief, internally determined, her conduct was impulsive, incongruous and bizarre. She wrote to the Family Physician and told him not to come and see her as he reminded her of someone whom she had 
loved but had been disappointed over.

Her stream of talk was along these lines. Q. What are you complaining of? A."I'm not complaining of anything. I've had a strain. I've built my mind on what I thought I ought to have built it on ...... I had the slights there...... Hugh's rather ..... He has totally misguided us. I think I've hurt myself. It's my flesh I'm blethering through ...... some hole up here in my shoulder ...... I think I've bullt a glamour round myself".

"There's a hole in my shoulder, but I've put determination in". "I'm all muddled up, and I'm not going to try to get out of $1 t^{\prime}$. "There's something pushed up through my body. It's a gift - a horrible gift. Most unhealthy".

"My imagination is working very vividly. It keeps me al1ve. It's all very nice and perfect. It keeps me from going absolutely blank".

She has continued in this way for over four years and the most marked feature of her illness is the haptic hallucinosis of an obvious sex type - pains shooting up the centre of her body, people stick things into her, especially the pianist with whom she had worked. Her affect loss is marked and her family have no claim whatever on her emotions.

Her hysterical palsy has now disappeared, but she constantly refers to her music master, and this in connection 
with her symbolised sexual experiences. Her psychosis is a grave one, and has all the signs of an acute schizophrenia. Her reality setting is entirely altered, and her affective responses exaggerated, dramatic and dissonant, with violent outbursts of tears or laughter, are all internally determined and show a marked disintegration of her personality.

Here, then, is a case whore a life difficulty was met by a neurotic reaction. Frustrated in her wish to go on working near to the object of her affections, she ceased to be able to work at all.

This reaction took place in a personality of a definite1y schlzothymlc type, described by Kretschener (21) as unsociable, quiet, reserved' furthermore showing the proud distance and haughty intenseness which, he argues, is a manifestation of this type.

It is noteworthy that, at the onset of the hysteria, a personality change was seen. She became more tractable and pleasant, and is described as being "nearer" to her family. In this we can see the belle indifference so characteristic of hysteria, and the picture of a neurosis is made even more complete She had, temporarliy, solved the chlef difficulty of her life. Finally, out of the hysteria, there emerged a full blown schizophrenia, which has maintained itself up till the present. It is a process of this kind which 1llustrates so well the meaning of the terms partial reaction, applied to the 
neuroses, and total reaction, applied to the psychoses. During the neurotic phase of her illness, this patient was reacting to a Ilfe difficulty in an improper way, but still a way which enabled her to maintain to some extent her grip on reality, and to live in a world resembling that of the normal individual. Her departure from the real was partial only, and her behaviour continued to be modified by the demands of reality. Her mind, to borrow from McDougall, was still a microcosm of the world. Now, in the psychotic stage, she has nothing to do with reality, and her conduct is all modified in response to phantasy and the activity of a complex.

This case has been quoted at some length, and perhaps this is excusable in that it illustrates, in a very definite way, several points which may be summarised as follows:-

(1) It shows the existence of a border-line type of case.

(2) It demonstrates (here with the most clear-cut of all neuroses - a hysterical palsy -) the existence of a neurosis as a stage in the evolution of a schizophrenia.

(3) It indicates the dynamic nature of the schizophrenic process as a definite response to a life situation.

(4) It vindicates the use of the terms partial and total reaction.

(5) Finally it is most suggestive, for in the personality we can trace the schizold tendency far back and can hazard a guess at this as being the determining factor in the end result, where neurotic solution to a problem is not satisfactory in a personality setting of a schizophrenic type.

Here the existence of a long-standing pre-existent neurosis has been of bad prognostic import. 
In "the psychology of Dementia Praecox" by Jung, the following passage occurs:- "As far back as 1893 Freud showed preliminarily that a hallucinatory delirium originates from an unfulfilled wish, and that this delirium is a compensation for unsatisfied yearnings, that the person likes refuge, as it were, in the psychosis in order to find, in the dream-like delirium of the disease, that which was refused to him in reality. In 1896 Freud analysed a paranold condition, Kraepelin's paranold form of Dementia Praecox, and showed how the symptoms were accurately determined according to the scheme of the transformation mechan1sm of hysteria. Freud then stated that paranola, or the group of cases belonging to paranoia are a defensive neuropsychosis, that is to say that just like hysteria and obsessions, they, too, originate from the repression of painful memories and that the form of symptoms is determined by the content of the repression". This finds striking corroboration in the case just quoted. It should not be forgotten, however, that when Jung refers to hysteria he includes in it what has been defined as the group of anxiety states.

The next case is of a less definite type, but it 1llustrates a similar mechanism in showing the advance of a neurosis to a schizophrenia with paranoid features and it is quoted here to show again the existence of a definite neurosis of long duration followed at length by a schizophrenia. Here we are dealing with an obsessional neurosis. 
Case II. Female, 30. The patient did not show her psychosis until she was thirty, and the breakdown took place suddenly enough while she was on a tennis court, at a crowded seaside resort, playing in the final round of a tournament, when she stopped in her tracks and walked of $f$ the court.

Thereafter, the condition rapidiy advanced, and now, two years after the onset, she is dominated by auditory hallucinations which are the obvious expression of hitherto suppressed drives of a sex type and her retreat from reality is marked.

It is the onset of the condition, however, which is of the most importance at present, for her schizophrenia is definite and established. It omerged in examination, that at the age of 17 a theft took place in her school, and she at that time experienced an affective disturbance of a marked 'unpleasure' tone. This continued all her life until the onset of the psychosis, and she declared that it was growing more and more urgent. If she heard of some petty theft or, earlier, if the culprit's name was mentioned, she would be thrown into a state of anxiety and fear, or if the thought of a theft came into her mind the same thing would occur and she sald that she began to wish that people could read her mind, so that they could know how innocent she was. The anxiety was definite, and had the physical components of tremor and tachycardia. Ultimately she reached a stage at which the thought of theft in all forms 
came constantly to her mind accompanied by the affects of anxiety and a feeling of guilt.

This naive remark that whe wished people could read her thoughts, which she made in almost these very words, indicates both a return to the concrete, feeling, perception level of the schizophrenic thought processes, and an indication of the probable factors at work in the aetlology of the neurosis. The attempt was unsuccessful to find the thought for which the theft idea had been substituted to carry the unhappy affect, but we cannot lightly discard the Freudian theory that obsessional thoughts arise from some sex experience: and this the more especially as in her hallucinosis the volces suggest sex activities of all kinds and state that she has performed these in the past.

The detail of her broakdown was simply that her partner casually mentioned that in such a crowd small articles were oasily stolen. This remark induced a panic, and she had to stop playing.

Thereafter, she felt that people were looking at and talking about her, and a volce accused her of laziness, of giving in to her obsession, and went on to suggest sex relations, saying, as already stated, that these had taken place in the past. Hor psychosis has advanced. By the time she came to hospital she had already been psychotic for about two years, and her condition was recognised to be growing worse. Within 
a few weeks of coming to hospital she showed a progressive deterioration of a severe type. Her conduct was entirely complex, determined and consisted of a response to hallucinosis, and she betrayed a marked falling of $f$ in social sense by wandering about nude in the drawing room in the part of the hospital where she was. Her affective responses were not determined by her surroundings and showed a dysharmony with her thought.

Here again, is a neurosis lasting from the age of 17 unt1l the age of about 28, at which time a psychosis begins to show itself. There are several points to be considered. Firstly, in connection with the aetiology of the obsessive compulsive nourosis there is a case showing a similar mechanism quoted by McDougall (22) where stealing and sex activity were linked up to produce an obsessional symptom grouping. He suggests that the furtiveness of both acts make them an easily substituted couple, the one for the other. It was not possible in this case to demonstrate the existence of guilty relations between the patient and the culprit in the theft, but it was known that they were great friends and this is of importance in connection with the patient's known sex trends, for the thief was a girl. And secondly, though her personality did not show schizold trends to a suggestive extent yet there was an ominous factor. Her birth and infancy were normal. She was healthy and her school and college life were successful. She was a good mixer and her attitude to herself and to others was stable. She played games 
a good deal, she was even tempered, had a keen sense of humour and was not over sensitive. Her attitude to the opposite sex, however, was odd; she had no men friends, she had never had a love affair, she expressed a repugnance to the male sex in general and this, with a tendency to shyness, suggests a homosexual trend. This, with the narcistic and maldeveloped components of such a trend, is suggestive from the aetiological point of view taken up by Hutchings, Cheney and Wright (23) and mentioned earlier.

These various pieces of evidence exist clearly. It is the difficulty of evaluation that is the chief obstacle. Be that as it may, this case shows a schizophrenia, declared for two years, and becoming more severe, which has been preceded by an obsessional neurosis lasting for eleven years.

The whole history of the case is easily analysed along the lines suggested by Jung (24). If we can accept the probabilIty that some sex trauma, or at any rate, incident, determined her neurosis, then the connection becomes clear between her early neurotic symptoms and the later psychotic manifestations. These, as stated, showed a marked erotic content, which was significant. The volce, which she said was that of a Commissioner of Police, probably a symbol of authority and masculinity, ordered her to have done with her obsession, told her that she was innocent, and later, commanded her to come to him as his mate. It is not too much to suggest that here is a complex determined turning 
away from a homosexual to a heterosexual attitude on a fantasy level, especially in view of her absence of heterosexual activity noted before.

Here, once more, is an example of the partial and total nature of the personality change in the neurosis and the psychosis respectively. The two phases of her illness may be regarded as a reaction to sex difficulties. In the first, the personality in its reality setting is properly oriented, for during the obsessional phase she continued at her work, in the second there is the characteristic turning away from reality so typical of the schizophrenic reaction.

An important consideration, the central point of the case, is that the psychosis grew in a connected sequence out of the neurosis and had a similar preoccupation in the patient's thought content and mental trend. That is to say, during both phases the topic was the same.

The points brought out by Case I.are here confirmed, with this proviso that, with the exception of a homosexual trend, there is not the same evidence of a schizold personality before the onset of the 111nesses.

The foregoing two clear-cut examples show an ordered progression of a deepening disorder which has become more and more ominous as the case has progressed, and where the neurosis has been a prodromal symptom. The next case shows a different progression of an equally important type. 


\section{Case III.}

This patient, a woman of 54 , was admitted to hospital with a history of illness dating back for about ten years. Her Iife story is essential to the proper evaluation of the details of her 1llness.

Abnormal trends were seen at a very early age. She had a normal birth and infancy, and her heredity is good, but she had to be taken away from school at about 16 because she was being bullied and her splrit was being broken. She was then kept at home and played a large part in the work of the house and in looking after the other members of her family. At this time she is described as being better than she has ever been, and this is interesting from the point of view of Adler's theorles, for at that time she was, as the oldest of the family, in a position of superiority. The home atmosphere, however, was a stern one, she had little outlet in entertainment or social life, and she gradually began to show signs of an autistic tendency. She became shut away and dreamy, was much by herself, and was of the type that "communes with nature".

She went to Canada to stay with a relation and remained a few months, then she came home and went to Dresden with a friend who was studying music. She remained there only a few months and came home, finally leaving home to go to London with no special object in view. At this point, in her early twenties, there is seen a disorder of personality integration evidenced 
by her constant shifting about from place to place. This became more marked in London. She became a Christian Scientist, she took up New Thought, Brighter Thinking, had an interest in Theosophy and so on. She did no work, nor did she devote her energy to any useful charitable organisation; she moved from boarding house to boarding house. She began to develop a "nervous breakdown", she was intensely unhappy and did not know what she wanted, often it was something unattainable and her condition sent her seeking treatment by several psychiatrists on one of whom she soon developed a strong fixation. The evidence is not clear but it indicates a part reaction of considerable duration of the type of an anxiety state. The duration of this state was of at least two years.

She finally broke down so badly that she was admitted to the Cassell Hospital for Functional Nervous Disorders, and here an interesting episode took place. She went into a Chemist's shop and sought protection against the spirits that were annoying her. A few hours later she denied this and was free from similar episodes for some months. This is a clear example of a schizophrenic episode in a neurotic setting and took place two years before she was seen by the author. At the time when she was in the cassell Hospital there was no Indication, save for this episode, that her condition was anything but a pure neurosis and it was said definitely that no psychotic features were present except for this episode which 
was suspected of being simulation.

Her condition progressed unfavourably, she was in various institutions for brief periods, and during the intervals she was well enough to live outside.

She finally was admitted to the Edinburgh Royal Asylum, and presented a plcture of an acute excitement. She talked incessantly, was restless, sleepless, emotional and querulous. Later she became somewhat depressed and just before discharge she complained of unhappiness, inability to concentrate, and of anxiety. In these we can see Janet's sentiments d'incapacito clearly illustrated. She was clear and co-operative at this time and went home, having been in hospital three months.

She remained at home for a month and was, at the end of that time, admitted to the Glasgow Royal Asylum.

She showed an interesting picture which was at first highly suggestive of a hypomania. She manifested flight, distractibility, an affective lability and she was surrounded by the profusion of laces, ribbons and odds and ends so typlcal of the hypomaniac. On closer examination, however, a more ominous trend was seen.

She told how she had been "splritually wedded" to a "Harley street physician", and that, during a vaginal examination, "something had been broken which had never been broken before" and that she was increasing in girth. She also sald her menses 
had stopped. All this, of course, indicated a wish-fulfilment phantasy of pregnancy, and she talked much of "The Mother Heart". She said "a woman is good for nothing unless she has been a Mother", and added, "one does not need to bear children to have the Mother Heart".

In conjunction with this came, sharply clear, her manifest thought content in sex affairs. "I never contacted with a man in my life - I was too proud - never let a man see I cared. If they squeezed me at dances I just finished with them". The slgnificance of this as the evidence of a cross current of sex repugnance and sex wishes is clear, and it is a characteristic schizophrenic attitude. It shows the ambivalence of Blouler (25), and as well it shows the essentially purposive comprehensible nature of the process. From the point of view of Jung we can see clearly the autonomy of the psychotic complexes with the corresponding diminution in the power and harmonious working of the ego complex hierarchy.

Her inclusion in the schizophrenic group is assured and for the present purpose we must look to her subsequent progress She became ocstatic and at that time said that she was to be formally married one day soon. Following this she became dull, depressed and began to show odd insight developments. She confessed to "day dreaming", sald there were times when she could not separate dream from reality; but in the same interview she 
expressed the opinion that the Resident Physician was not who he was supposed to be, and hinted that he might be her mysterious lover.

At that time, too, she showed a grandiosity. She said that she had appointed one of the nurses to be her Lady-inWaiting and hinted at future splendours. This was at a stage when she was returning to a better contact with reality. Now It is suggested by Freud that these grandiose episodes are due to a fixation of free libido on the ego complexes, and this liblio here had been temporarily freed as a result of the lessened insistence of her pathogenic complexes. In such cases a stage of even greater libido freedom is the basis of the neurotic transference.

From now on, however, her reaction diminished progressively in totality and finally she developed a frank neurosis or "part reaction", and this was a hypochondria.

The plcture was falrly complete, except that from the affective point she showed rather more querulousness and annoyance than Gillesple (26) would allow, indicating, as he does, 'interest' as the affective component of this syndrome. She complained about the food, and the absence of proper constituents in her dietary. She had a good deal of 'popular' diatetic information and she spoke at length of the faulty elimination that her low residue diet was producing. She declared that she 
was obstinately constipated, (this was true in part), that she felt 1 ll and vaguely nauseated, that her colon was loaded and stagnant and that her abdomen was becoming distended. The presence of anxiety was fairly definite in the existence of an agitated trend. At this time, attempts to discuss her psychotic trends met with a great resistance which could not be overcome, and she showed, in her behaviour, no evidence of their activity. As to the existence of hypochondria in its own right much dispute exists. Gillespie (27) states that it does exist as an entity, but the case for regarding it as a sub-group of the anxiety states as already indicated, receives much more common clinfcal support. Gillesple speaks, however, in the connection here considered of ".... a hypochondriacal development of an abnormal personality; it is still hypochondria and it is not correct to consider the hypochondriacal ideas in such instances 28 part of the larger syndrome. It is more accurate to speak of hypochondria in a schizoid personality; the additions of the pure hypochondriacal plcture depending not on a new concurrent development but on pre-existing oddities of personality".

The caso described lllustrates this clearly, but it shows more than that in the striking similarity of the patients' reaction to a situation at two different periods. During the phase of total reaction when her reality contact was diminished, or, to put it in another way - when her ego complexes had less 
control of the total psychic situation, her abdominal condition meant for her a pregnancy. Later it meant merely abdominal stasis, but the idea had a disproportionate affect tone.

Her personality was clearly a schizold one from an early date. For a period before the development of psychotic symptoms we have evidence, unfortunately lacking in detall, of an anxiety state, then we have a psychosis where, as so of ten happens, we can see the mechanism at work and, during a remission, a partial reaction is seen with neurotic symptoms, having an obvious relationship to the psychotic complexes.

From Jung's (28) point of view it would be said that the ego complex was beginning to reassert itself; Meyer would Indicate stronger reality contacts; it would be agreed that a redintegrative process was at work.

This hypochondriacal reaction - to use a more elastic nosology - persisted, but lessened gradually for some months, and the patient finally left the hospital, having made a roadjustment which seemed fairly secure, and she has since been able to live on the outside with success.

The three instances given have been quoted at length in order clearly to illustrate the process under discussion, and the $\mathrm{all}$ do so definitely.

The points which emerge arise in aspects of personality and in the similarity of the neurotic and psychotic symptoms to 
each other as a means of escaping from a difficulty. Each developed a neurosis out of which came a psychosis. In each case a connection could be traced to a common origin in a defect of adaptation of the patient, as a psychoblological unit, to the total life situation.

Macfie Campbell (29) Justifies the conception of personality and psychosis as being made of the same stuff. Here, evidence is shown which justifies personality, neurosis and psychosis, as being factors and stages in the same process of malreaction, and, to continue the simile, made out of the same materials.

If it is true to say that a neurosis and a psychosis show a qualitative and quantitative difference, but are the same essentially, as failures to respond along socially accepted lines, then also, the cases quoted indicate that the same difficulties may produce a psychotic or a neurotic response.

The behaviour of the patient, the sum of his activities, show clearly the working of the same complexes but with, in the neurotic periods, a less degree of power on the part of the pathogenic complex over the total personality. It becomes very evident that the essential difference between the neurotic and the psychotic stages is one of degree and quantity rather than a pure difference of quality.

A great deal emerges from the study of these cases. 
The most important point, however, is the cormon origin of neurotic and psychotic responses already stressed.

Jung (30) indicates that in Schizophrenia and other reaction types, the most bizarre, and apparently meaningless, behaviour has a meaning for the patient, obscured from the observer by the condensation and symbolisation which is so typical of complex determined thinking. In many cases this obscurity is impenetrable, and only occasionally are we so lucky as to get information the like of which enabled Jung to explain the mysterious hand rubbing of his old schizophrenic woman in Burgholzte who had had a fruitless love affair with a shoemaker whose movements she had ever since imitated. The cases quoted, however, do not offer any difficulty and the $y$ all show clearly what has been going on in the patient's mind.

The first case, disappointed by a person on whom she had a considerable fixation, developed a palsy affecting that bodily activity which was an integral part of the constellation of ideas grouped round the person on whom she was fixed. This, only a partial curbing of the function of the real, did not solve her problem and she diminished still further her dependence on reality in a retreat and she began to find "in the dream-like delirium of the disease that which was refused to him" (in this case, her) "In reality". (Jung).

The second case escaped from an obsession on a homosexual basis into a phantastic world of strong heterosexual 
contents.

The third case manifested an early anxiety state. We are entitled in view of the whole case to lay this at the door of ungratified sex wishes. In this she developed a fixation and from it she passed into a delirium of the most obvious wish fulfilment, and later on, when the function of the real became greater, she utilised the same bodily symptoms to support another contention. It cannot be denied that nausea, constipation, and increase in the size of the abdomen, are associated in the lay mind with pregnancy. It is very striking that she brought them forward frankly as symptoms of an abdominal hypochondria shortiy after she had evidenced abdominal distension as a sign of pregnancy, and had in addition mentioned the cessation of her menses.

A second point is the personality of these three cases. Two of them gives justification for its inclusion in Kretschmer's (31) group of Schizothymes, personalities out of which a schizophrenia may easily develop. Bleuler (32), it will be remembered, says that he can see schizold traits in everybody, but in the personality of the patients here considered, there is more than merely a schizold trait. The personality picture obtalned of two of the three was that of the "unsociable, quiet, reserved type" (Kretschmer) and case 3 in addition shows the Kretschmerian type "timid, shy with fine feelings, sensitive, nervous, excitable, fond of nature and books" in a very marked 
In case one we can detect, if not a definitely schizoid trend, at least an ominous type of sex development. Aetlologically we are faced with a more suggestive set of factors. In case $I$. there is definite evidence that a single trauma produced the onset of that hysteria which subsequently took so ominous a turn. In case II.there is evidence of a long standing obsessional state, which culminated in a schizophrenia where the "disease complex" (33) seems fairly definitely to have been a battle ground of homo and hetero sexual impulses. In case III, however, we know of no trauma; environmentaliy, the patient was, in a way, botter off than the other two, for she was allowed to live her own life which she had done, as has been shown, on a low social-demand level. She had little to live up to and could go her own way. Her responsibilities and duties had been nil. Now, this third case shows at the beginning what we may judge to be an anxiety state, and as a remission, a hypochondriasis associated with some anxiety. The other two cases show no signs of readjustment, while she has made a recovery which, if partial, is yet sufficiently good to re-create a self-environment relationship and allow her to live on the outside. Cases one and two, on the other hand, had definite tasks to perform and considerable social duty. Case I.had found her 'occupation gone' while Case II., It w1ll be remembered, was urged by her complex, acting as a hallucinosis, to go back to work. 
We can therefore trace here, in the two graver cases, common factors in the presence of higher occupational demands than were imposed on the third.

The case now to be quoted shows a complete and maintainod recovery in a schizophrenia with neurotic symptoms in the prodrome.

Case IV. A young man of 21 , a medical student, took suddenly 111 and was admitted to hospital in a katatonic excitement four days after the onset of his breakdown.

When all the evidence had been amassed, his history showed much more than at first appeared. He was admitted in January and, it was said, had showed no signs or symptoms of 1llness up to four days before admission, but 1 t was discovered that for over four months, pathological trends had been present. In the preceding August he had become silent in company where before he had been reasonably lively, he began to go "off his game" at tennis, he did not take his food well, he was excited and "nervous".

The University session began a month later, and he began to show additional evidence of inability to react successfully to his environment. He was in his final year, but he began to feel that he could not go on. He developed headaches, his head buzzed, he was tired, he could not concentrate and he was unable to comprehend the lectures. Theroupon, without further ado, he gave up medicine. 
A neurasthenic syndrome was here, fairly obvious, and there was in his life situation, a casual factor. This was the breaking off of a love affair just before the session began. Yet this was not all, he was informed by an insurance examiner that he had a defective heart valve and he developed a severe insomnia which lasted until his final breakdown.

In spite of everything we cannot disregard these traumata.

Having been forced thus to give up medicine, he declared that he was fit only to be a tramp, but managed to go into an office in town where he remalned until his breakdown.

Further investigation of his love troubles showed that he had broken it off through jealousy, and that the girl had encouraged him out of pity for his solitariness. He had further declared that he was not fit to marry because of his heredity. His Father had Parkinson's Disease and a maternal aunt had been psychotic. All this, combined with a possible degree of dissatisfaction with his medical studies, had made a mileu out of which a neurasthenic reaction had arisen as a mode of escape. At this point we have to consider, in view of the events, what sort of personality formed the soil on which this growth took place. The evidence is essentially negative. He was described as cool, not easily irritated, he played golf and tennis sufficiently well, he was a good average scholar, he was not moody, he was not hypochondriacal, in behaviour he was 
typical of his age and position, he was rather easily led. only in the statement that a girl tolerated his advances out of pity for his loneliness, is there any evidence of abnormality.

The onset of his illness was sudden. His insomnia became more severe, and he had to take Bromide. One morning he swayed and seemed about to faint but recovered himself and said "I have been a revivalist for a few minutes". That day he was confused, forgot what he had to do, and said that he had felt muddled for the past few days. Thereafter he rapidly developed a typical katatonic excitement.

The particular significance of the case was that, during the excited phase, his stream of talk and his mental trend were tenanted by preoccupations that appeared to have operated in the production of his neurasthenic syndrome.

He said he had no heart and repeatedly asked confirmation of this. He talked of his own powers, intellectual and otherwise, of his will power, and of his wish to succeed, to earn money, and to marry the girl already mentioned. Shortly afterwards, when he had retreated sufficlently from reality to place his thinking on a frank phantasy basis, he described himself as the possessor of a car, and he named the make, married to his girl and qualified as a Doctor. He said he had qualified at the age of 21 .

This was an obvious and open wish fulfilment mechanism of a schizophrenic type. He was, as Jung (34) puts it, dreaming 
with his eyes open. The dream simile goes further for he showed phenomena of condensation and symbolism of the dream thinking type. He had a vision of a skeleton wearing a helmet decked with a $\operatorname{rose}$ and he interpreted this to mean that one ought to make the best of things.

He showed flexibilitas cerea, perseveration of the phrase "It's all right" and of actions, and his thinking was so complex determined that he became incoherent because of the accompanying association defect. A sample of his talk is as follows: - "colour - till - alp - Wm.o'Brien - student of myself - pin - I can - Bit - anybody - name".

These points indicate how severe a schizophrenia was present.

There is, in this case, ample evidence to show what had taken place. Life, and its demands, had proved too much for this young man. He had been unable to live on a reality level sufficiently to face up to sex difficulties and the strain of his studies: as a faulty response he developed a nourasthenic syndrome along the dynamic lines which Adler (35) suggests, as an excuse, as it were, for his incapacity. But the process went a step further. The neurotic reaction did not solve his equation. Why, we do not know. Perhaps it was because in the Meierian term it was only a part reaction, and tending always to be unstable. Perhaps his amour propre, his self-regarding sentiment, would not tolerate such an avenue of escape. At any rate he fled 
from reality into a total reaction of a shizophrenic type, where the whole situation was made smooth by the development of suitable phantasies with regressive phenomena in his thinking.

Gradually the katatonic excitement, with its push of talk, attitudinising, hallucination (not marked), flexibilitas and perseveration, died down. He became dull, automatic, foollsh. The prognosis appeared bad. He was discharged somewhat better but obviously disintegrated, apathetic and with autonomous complexes in existence. His "fonction du reel" had been much disturbed; his talk was as follows on leaving hospital:"Where are you going?" "I don't know".

"How long have you been here?" "About a year" (six months actually)

"Why did you come here?" "To strengthen myself".

"What was the matter?" "Weak heart".

"What are you thinking of?" "Nothing in particular".

"Where are you going?" "I don't know".

"Are you glad?" "Yes", unemotionally.

The typical affect loss is well shown.

He went home, however, and gradually recovered. He is now, seven years later, working as an engineer and taking a normal place socially and economically.

The case shows the development of a neurosis followed by the appearance of acute psychotic symptoms which although of an ominous type, yet went on to a recovery and not merely a readjustment. As in the three cases quoted, the aetiology is 
clear enough, and there is evidence of the same preoccupations running through the nourotic and psychotic periods. And again, as in the other examples, we have to review the sequence of events in the light of our knowledge of the patient's make up. Granting the truth of Bleuler's statement, quoted earlier, that schizold trends are visible in all, there is not, in the personality of this patient, a sufficient preponderance of such trends to justify the label of schizothyme. He was a falrly good mixer, a games player, a healthy fellow who had boen successful in his studies up till his final year as a medical student. The singlo reference to a solitary tendency may therefore be given the little weight it deserves.

Thus there is some grounds for supposing that the readjustive factor has in this case been the negative one of absence of a definite personality reaction of a schizold type, and even in spite of his "katatonic jolt" (36) this factor has been sufficlent for the purpose.

It must not be thought that the cases quoted are an envisaging of casual nourotic manifestations in a psychotic setting. This occurs so constantly that it needs only to be mentioned, and the implication of the incidence of such trends has been recently taken up by suttle (37). His point, however, 18 the insistence on the value of these neurotic trends as a therapeutic point d'appui where a frontal attack on paychotic structures is hopeless. At the same time, in his series of 
three cases, one feels that the various trends were epi-phenomena on a basis of an essentially schizophrenic reaction type and that, in such instances, anxiety, obsession, paranoid trends and what not, occupy an analogous position, in relation to the undorlying schizophrenia, as fever and tachycardia do to a multitude of bodily diseases. We should remember here the distinction between a temporary symptom complex and the actual underlying disease, noted by Kahlbaum.

It is only when we have, at a given time, a sufficiently clear plcture of neurosis alone, or psychosis alone, that we can envisage a genuine, though gradual, change in reaction from "part" to "total". Suttio suggests a difference in "tension", which he says may be "neurotic rather than psychotic in nature". It is difficult to see what he means by this, and the only interpretation which allows of the conception of a progressive increase in ominousness, is by taking "tension" to indicate the endopsychic coherence a la Janet (38). It would seem better to regard the change from neurosis to psychosis in terms of a personality disintegration where the disease complex, on the constellation of Ideas of a pathogenic nature, gains a gradually increasing degree of governance over the total organism at the expense of the ego complex with the consequent production of a "total" (psychotic) reaction.

The therapeutic point which suttie does not mention 
is the fixation of libido. At a neurotic level there is sufficlent free libido to allow of a transference and endow the physician with a large measure of therapeutic power. Later, when the libido has been entirely pre-empted by the pathogenic complex this transference and consequent therapy is not possible. 


\section{ANALYSIS OF 100 CASES.}

In order to study the incldence of the type of case under discussion, a series of over 100 schizophrenic reaction types were carefully gone over, from all the points of view that the anamnesis would permit.

The series was divided into two groups; (A) readjusted socially and recovered, on the one hand, and (B) non-recovered cases on the other.

The cases already quoted emerged from the total material, which was taken without selection from the records, so as to give as true a percentage as possible. As well as these, a series of cases of a similar, though less clear cut type, appeared. One of these illustrates the type of mechanism suggested by Suttie, in his paper on neurotic superstructures, already quoted.

Case V. The patient here was a girl of 26, an office worker, who had, all her life, shown evidence of a degree of "shut in" tendencies sufficient to justify her inclusion in the group of schizothymes. She had manifested also a lack of normal sex development at a heterosexual level. As a result of very mild 
"attentions" from a man in her office, she developed a paranold syndrome as a 'situation psychosis', but in the prodromal period she showed for some weeks a marked affective response with anxiety, which was sufficiently definite to be commented upon at the time, and may accordingly be regarded as an anxiety state. The affair progressed steadily, however, and deepened into a severe schizophrenia with features of katatonia, regression and complete divorce from reality contact which has lasted 8 years. Suttie suggests, of course, that if, at the time of the neurotic reaction, a push is made to treat the neurotic symptoms, the progression may be arrested. These cases are, however, not common and the transitoriness of the different stages is such that one feels that therapy directed to the neurotic element would need to be powerful and rapid to break the sequence.

of the total group of cases, twenty-nine made readjustments and these readjustments have been maintained in twenty-two, who have therefore recovered, while seven have made a social readjustment only, and are not functioning members of society, although not in hospital.

Out of this group of twenty-nine, it was found that a total of nine cases showed sufficlently marked symptoms of a neurotic type in the prodrome as to justify their inclusion in the varlety of cases under consideration. Although not so arresting as the first four cases quoted, and although unfortunately 
we are hampered by the fact that these cases were not all examined with the present point in view, yet the principle of the neurosis-psychosis progression is clearly illustrated. Briefly these cases were as follows:-

Case VI. A man of 36 , of somewhat schizothymic personality, started a business of his own. Competition was keen, and he was a novice. There was a good deal of worry on a reality basis and he developed an anxiety state. He showed sleeplessness, anorexia and anxiety for about a week. He then developed a paranoid syndrome, became suspicious and felt he was being watched, and in a few days he lapsed into a stupor, from which he emerged in a month to make a complete recovery in six weeks. Case VII. A man, also 36, who had no signs of a schizothymic personality, developed a series of colds, and following that he showed a neurasthenic syndrome with headache, lack of energy and irritability. This condition lasted two years without any evidence of a psychosis and he continued his work and at the end of this time he began to show apathy and to have visual hallucinations. Later he developed a katatonic excitement. Six months from the onset of the psychotic symptoms he recovered completely.

Case VIII. A man of 23 , of schizothymic personality, had depression, loss of concentration, loss of weight and no psychotic manifestations for some weeks. Suddenly he declared that he was ruined as a result of masturbation, God had deserted 
him, he made a series of very determined suicidal attempts and became stuporose. He made a recovery in under a year.

Case IX. A woman of 40 , with no positive personality points, feared pregnancy after an illicit intercourse, and developed a typical neurasthenic syndrome with headache and fatiguability, which lasted for some weeks. She then became confused, suicidal, and heard accusatory volces calling her names. Four months later she recovered, and was well for ten years when she developed an exactly similar attack, from which she again recovered.

This case is especially interesting. She accused herself for her moral laxity in the beginning, and while the pathogenic complex (1.e., the associations of her illicit sex relations) was still in consclousness she was able to react on a "part" or neurotic level; a process of repression, however, it would seem, endowed the complex with a greater degree of autonomy and it emerges as an accusatory hallucinosis. The Important point, however, is that ten years later, although the length of the interval, in the light of our knowledge of complex duration, does not matter, she showed exactly the same progression From a constitutional point of view this is significant. Case X. A man of 28, not schizothymic, developed a hypochondria with associated anxiety. The hypochondriasis became fixed as a delusion of physical disease and he began to show evidences of a schizophrenia. He made a complete recovery. Case XI. A woman of 32 , of a schizothymic personality, 
developed a simple depression which lasted about ten days. She then became paranoid, and had katatonic periods, but at the same time she showed a marked degree of anxiety. She recovered after 18 months.

This case is quoted as evidence of the overflow of part reaction into a total setting. There is always some degree of this but it is strikingly illustrated here where in a paranoid setting a strong affective reaction is seen. It should be noted in this connection that suspiclousness has been declared not to be an affect. This is debatable and Blanchi and others definitely describe it as an affect.

Case XII. A woman of 26, of schizothymic personality, developed a depression of the anxiety type, which lasted, uncomplicated, for four months. She then developed a paranola with apathy, and withdrawal from reality, which only held for two months, when she recovered.

From the non-recovered cases, the following examples emerge.

Case XIII. A man of 43 , of a schizothymic personality, developed an anxiety state which lasted for some months, after which he became stuporose and developed a katatonic type of schizophrenia which has maintained itself for thirteen years.

Case XIV. A man of 28, of a psychopathic trend, developed a fatigue syndrome of neurasthenic type, which gave way after some weeks to a severe schizophrenia, with negativism and 
regressive phenomena, from which he has not recovered.

Case XV. This case, like Case 9, 1llustrates the occurrence of more than one breakdown of the same type. The patient was a gunner, R.G.A., aged about 35 , and on two occasions, while in France, he developed an anxiety neurosis, for which he was treated in hospital. He was discharged in 1918, and resumed his civilian occupation, but only for a few weeks, when he again fell 1ll. His symptoms were "weakness, sweating and anxiety". After a month of this, he developed a paranoia directed chlefly to his wife. Later he had auditory hallucinations and he was incoherent and impulsive. From this severe attack he recovered, but a few months later disappeared from home in an automatic state, which was authentically an hysterical fugue. After this he developed psychotic symptoms of the same type as before, which have maintained themselves for six years. There was no evidence of any abnormality in his personality nor could he be described as a schizothyme.

Case XVI. A girl of 27 , not abnormal or schtzothymic, developed hypochondria which lasted six weeks. She then became mute, negativistic and katatonic and has not recovered.

Case XVII. A young man, in the early twenties, of a schizothymic trend, had three schizophrenic episodes characterised by negativism and katatonic excitement. The last attack has not been recovered from. The first attack lasted four months, the second attack, four years later, lasted six months, 
and the last attack began three years after the preceding bout. Eetween each attack, and before the first he had an anxiety syndrome, and the psychotic episodes were not marked by any affect of that type.

Here again is an example of the same progression taking place in the same individual on several occasions.

Case XVIII. A young man of 25, not a schizothyme, or of psychopathic trends, developed a respiratory neuroses of the type described by Dejerine (39). He had a respiratory irregularity, choking sensations, he was sleepless, had anorexia, was irritable and excitable for two years. The picture is one of a functional nervous disorder of the neurasthenia type.

At the end of two years, he began to develop psychotic symptoms. He had lost his Mother and he refused some medicine which, he said, was the same as had been used to poison her with. A few months later, he became incoherent and katatonic and has been so now for over 9 years.

Case XIX. A young man of 28, a psychopath but not definiteIy schizothymic, developed a neurasthenia. This lasted a month. Then he became mute, hallucinated and expressed ideas of domination. He made a slight degree of readjustment.

Case XX. A woman who broke down at the age of 32 , showed, for a year before the declaration of her psychosis, a hypochondriasis fixed on her abdominal organs. She became faddish about her food and took a great interest in vegetarianism. 
At the end of this period she became paranoid, in a few months was hallucinated, and is now, four years later, seclusive and regressed, so that her speech is meaningless and fantastic. Her personality showed no omlnous trends.

Case XXI. A woman of 45 , with a normal personality, developed a neurasthenic syndrome as a result of stress in her work, and this lasted for about 18 months. Then she developed a paranoia with haptic hallucinations which has since maintained itself.

Case XXII. A woman of 32 , who had shown no psychopathic trends in previous life and had been happily married for eleven years, developed an anxiety state in the third month of her second pregnancy. She was sure something dreadful would happen at the labour, (the first had been quite easy) and that the baby and she would die. She became depressed, fearful and agitated, and remained so for the next six months. Her child was born, the labour was easy and she was well for elghteen days, at the end of which she imagined that the nurse was trying to poison the baby and she tried to cut her own throat. Theraafter she became more disordered. The child became 1Il, and she made him worse by foolish and frantic attempts to make him eat. She neglected all else, she became shut in, negativistic and careless of her appearance. Thereafter her reaction became katatonic, and she showed marked stereotypy and perseveration, the content of which was constantly her baby. "Baby George X. ..... is now 
14 months old. He is living with his grandmother at number $X$, Y Street, Z ...". She would repeat this over and over again. She had been 111 for a short period, about two years, but her condition has been deteriorating steadily, and has an ominous appearance.

Here again, even on the surface, it is obvious that the preoccupations or thought content have been the same during the neurotic and the psychotic phases of her illness, and that each phase has been a reaction to the same factor.

Case XXIII. A young man of 22 , who had shown no psychopathic or schizothymic trends, developed nasal trouble. He had an operation for this, and thereafter became hypochondriacal. The anxiety component of this was not marked and the affective part seems to have been the "interest" which Gillespie stresses in his paper.

The hypochondria lasted for a year, and then merged Into a delusional system. He stated he had two hearts, he said he could cause others to die and to come to Iife. He became disintegrated, laughed and smiled to himself and in this way lapsed into a severe schizophrenia, which has maintained itself ever since.

Case XXIV. A man of 40 , who had been of rather a sol1tary disposition, but who had done well along social-economic lines, broke down in the Army and was in hospital with an anxiety state. He recovered and continued to serve in the Army for three years. 
on coming home, he gradually developed a schizophrenic reaction where the chief feature was a hallucinosis. He has become more and more demented during the past ten years.

Case XXV. A man of 28, of normal personality, developed a "war neurosis" of the anxiety type, diagnosed as such, and recovered. Six months later he developed a schizophrenia from which he has never recovered.

Case XXVI. A man of 28. This case is of interest in that the schizophrenia he ultimately developed is worthy in a way to be called a prison psychosis". The patient was an exceptionally good all round character, and showed no abnormalities whatever. He was a good worker in civilian life and made a success of all his activities, both work and play. He joined a Guards Regiment, and was captured in December 1914. He had a hard time as a prisoner, and began his captivity with three weeks' solitary confinement on bread and water, as a reward for what he described as "giving lip to Prince Rupprecht" when that person was interrogating him.

When he came home he was thin, "fumpy", easily tired, suffered from palpitation, could not stand noise of any kind. He lost his concentration, and could not carry on his work. About six months later, he became dominated by his pathogenic complexes and showed homicidal trends.

To-day, over ten years later, his personality is well retalned and he is usually on parole. Every four or five weeks, 
he becomes dangerous and strikes out, and at these times he is hallucinated.

\section{ANALYSIS OF FIGURES.}

Th1s group of cases from No.13 to 26 , with cases 1 , 2,3 and 5, make a total of 17. The total figures, analysed, yield the following results:-

Out of a total of 100 cases of schizophrenia, it was thus possible to demonstrate 26 examples where the reaction had been neurotic at first and later psychotic.

Twenty-nine cases recovered or readjusted from the schizophrenia and of these a neurotic syndrome appeared in nine, giving, a percentage of 31 .

The seventy-one non-recovered cases showed a neurotic syndrome in seventeen of the series, giving a percentage of 24 .

It is not possible to argue from a series of cases of this size, but the figures at least indicate that the presence of an early neurotic syndrome is not necessarily of grave prognostic import, even though there is a progression from a less to a more serious type of reaction.

It should be noted that out of the total case material a much larger number of cases emerged showing isolated neurotic symptoms. The existence of such is a commonplace of psychiatry and the existence of an affect of perplexity and worry is seen prodromally in all of the psychotic reactions. Here cases have only 
been quoted who showed such a sufficiency of symptoms or such a grouping as to justify the use of the term syndrome.

An attempt to estimate the "make up" of the patient has likewise been inconclusive. Out of the recovered group of nine cases, five are recognised as having ominous personality traits: while of the seventeen cases from the non-recovered group, only six were recognised as being of a disposition out of which we are accustomed to see a schizophrenia arising. Here again, we are not entitled to dogmatise. It is possible that some of these cases have only reached a schizophrenic reaction, for them not an obvious way of escape as in the definitely schizothymic, through the intermediate stage of a neurotic reaction, paving the way, as it were, for the full blown complex autonomy of the schizophrenic. The proportion of the neuroses appeared as follows:-

In the recovered group, Hypochondriasis 2; Neurasthenic syndrome 3; Anxiety state 4.

In the non-recovered group, Hysteria 1; Obsessional neurosis 1; Hypochondriasis 4; Neurasthenic syndrome 4; Anxiety state 7. 


\section{CONCLUSION.}

If we accept hypochondriosis as a sub-group of the anxiety states, and clinically anxiety is frequently part of the hypochondria syndrome, it will be seen that the anxiety group forms by far the largest number of the neuroses found. It is not too much to suppose that this affective response is the expression of conflict, and the inhibition, or frustration, of certain 'drives' or instinctive urges. At a later stage these instinctive urges become autonomous in the appropriate complex setting. The psychosis becomes declared, the affect, as Jung (40) has pointed out, becomes fixed in the appropriate psychic sphere and no longer reverberates into other activities as the free floating body of anxiety which is seen in the anxiety state.

The process is analogous to the psycho-logical process suggested by MCDougall (41). One or more instinctive urges may be integrated together to give power to some constellation of ideas and this constellation he calls a sentiment. Here, where we are dealing with the abnormal, the constellation of ideas is not in harmony with the aims or needs of the individual in his relations with his environment, and it is called a complex. A revolution of the 'body politic' takes place and the complex becomes a separate state with complete control of the personality all the time, or from time to time.

McDougall's hormlc psychology is widely accepted, and in 
this way it can be seen to fit with accepted views of psychosis formation. It is possible to regard the anxiety state as a sort of half-way house in the process.

The other neuroses which have been found to exist, also evidence the process of complex formation, and the step from neurosis to psychosis can be regarded as a progressive increase in the autonomy of the group of ideas originally operating to produce an abnormal reaction.

The age and sex incidence of the condition cannot be made significant, for in the recovered and non-recovered group the average age works out at 30 for the age of incidence of the psychosis. In the seventeen non-recovered, ten were males and seven females, while in the nine recovered, five were males and four females. Here the preponderance is male, but it cannot be regarded as anything but a suggestion.

In the type of psychosis we find what would be expected. Hebephrenia, the most definitely age-bound of the schizophrenias, is not seen. Out of the 17 non-recovered cases, seven were paranold, five showed a prominent katatonic phase, and four were of the simplex type. In the recovered group, on the other hand, six were paranoid, one of the six having a katatonic and one a simplex trend, while the other three were predominatingly katatonic. In both groups the paranold type was in the majority, while the others were katatonic or simplex. There is, therefore, little inference to be drawn except that the proportion is roughly the same as in the whole group of 100 cases where the 
paranoid type is in the majority.

The points of importance are that a progression not uncommonly takes place, from a neurotic to a psychotic reaction. The neurosis may be clear cut, and may exist as a condition in its own right, without psychotic features for a considerable period of time. The preoccupations and content of thought can be shown to be the same during the neurotic and the psychotic phase, giving evidence that the same psychological factors may operate to produce either a neurosis or a psychosis. It is suggested, therefore, that the difference between neurosis and psychosis is, not entirely, but in a large measure, one degree in the same process of malreaction to some psychic difficulty, which has not been solved with the ald of a proper self-environment relation. The findings give grounds for a more cautlous view of neurotic reactions, and a not universally pessimistic attitude to the schizophrenic. We get a vivid glimpse, in both types, of an attempt on the part of the patient to solve a problem, to satisfy an equation. The process, however inimical to social and economic success is yet purposeful, and we gain a sympathy and understandIng from this aspect of 1 t.

The study of these cases in detail, and as a whole, yields little significance to the discovery of how large a number of schlzophrenics begin as neurotics. Certain of the cases indicate that a long established neurosis, which ultimately develops into a psychosis, is of bad prognostic import. Cases 
1 and 2 show this especially clearly. Others of the case material, however, point in a direction which seems more likely to lead to the truth. These are cases 3,9, 15, 17. of these, Case 9 certainly and Case 3 , to a less extent, recovered, while Cases 15 and 17 have not done so. These cases, it will be remembered, showed the neurosis-psychosis progression more than once in their history and this can only point towards a constitutional reaction. The problem has no universally applicable formula with which we can solve it and we are forced to realise the truth of what Wernicke (42) said when he pointed out that fifty totally different reactions could be described and then another fifty just as different. Put in another way, it is Jung's (43) dictum that the mechanism of the psychosis is essentially an individual psychological process.

It may well be that, as time goes on, with ever accumulating items of knowledge, with wider interest in the subject, and more thorough case investigation, problems of endowment and environment will emerge and help us to some greater measure of prognostic power.

In a large measure the promise of prognosis may be in future implemented by the creation of organisations in closer touch with, and part of general hospltal groups. By the creation of such, therapy could be brought to bear at an earlier stage. Whether or not available libldo for transference to the therapist be the reason for what degree of success we have in the treatment 
of the neuroses, yet we are better able to help the neurotic than the psychotic. It may be that in future we may more of ten prevent the neurotic from finding that his neurosis is not an adequate solution to his difficulties, becoming psychotic and thus constituting a dead loss to society. 
(1) Kraepelin: Dementia Praecox.

(2) Kraepelin: loc.c1t.

(3) Henderson and Gillespie: A Textbook of Psychiatry.

(4) Blouler: A Textbook of Psychlatry.

(5) Henderson and Gillesple: loc.cit.

(6) Kraepelin: loc.c1t.

(7) Henderson and Gillespie: 10c.cit.

(8) Kraepelin: loc.cit.

(9) Meyer: "The Evolution of the Dementia Praecox concept"; "Schizophrenia".

(10) Meyer: Ioc.cit.

(11) Yellowlees: Proceedings of Royal Soclety of Medicine, Section of Psychiatry, April 1929.

(12) Henderson \& Gillesple: loc.c1t.

(13) Meyer: loc.cit.

(14) Henderson and Gillespie: loc.cit.

(15) Bianchi: A Textbook of Psychiatry.

(16) Blouler: A Textbook of Psychiatry.

(17) Hutchings, Cheney and Wright: Psychogenic Precipitating Causes of Schizophrenia: "Schizophrenia".

(18) Brill: The Schizoid concept in the Neuroses and Psychoses; "Schizophrenia".

(19) Sullivan: Affective Experience in Early Schizophrenia; "Schizophrenia".

(20) Kretschmer: Physique and Character. 
(21) Kretschmer: Physique and Character.

(22) McDougall: An Outline of Abnormal Psychology.

(23) Hutchings, Cheney and Wright: loc.cit.

(24) Jung: Psychology of Dementia Praecox.

(25) Bleuler: loc.cit.

(26) Gillesple: Hypochondria: Its definftion, Nosology and

Psychopathology, Guy's Hospital Reports, October 1928.

(27) Gillespie: Hypochondria.

(28) Jung: Psychology of Dementia Praecox.

(29) McFie Campbell: On the Definition or Delimitation of the Schizophrenic Type of Reaction; "Schizophrenia".

(30) Jung: loc.c1t.

(31) Kretchmer: loc.cit.

(32) Bleuler: loc.c1t.

(33) Jung: loc.cit.

(34) Jung: loc.cit.

(35) Adler: The Neurotic Constitution.

(36) Kretschmer: 10c.cit.

(37) Suttie: Neurotic Superstructures in the Psychoses; Journal of Mental Sclence, October 1928.

(38) Janet: The Major Symptoms of Hysteria.

(39) Dejerine and Gauckler. Psychoneuroses and Psychotherapy. (40) Jung: 10c.cit.

(41) McDougall: An Outline of Psychology.

(42) Meyer: A Review of Psychiatry. 
WORKS CONSULTED NOT REFERRED TO IN THE TEXT.

Adler: Study of organ Inferiority and its Psychical Compensation.

Bleuler: Theory of Schizophrenic Negativism.

Clouston: Mental Diseases.

Dertum: A Clinical Manual of Mental Diseases.

Freud: Introductory Lectures on Psycho Analysis.

Hart: Psychopathology

Hitschmann: Freud's Theorles of The Neuroses.

Ross: The Common Neuroses.

Stoddart: Mind and its Disorders. 